\title{
Comparison of neuroprotective effect of isoflurane and sevoflurane on cerebral ischemia
}

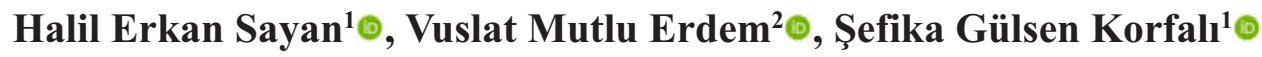 \\ ${ }^{1}$ Department of Anesthesiology and Reanimation, University of Health Sciences, Bursa Yüksek İhtisas Training and Research Hospital, \\ Bursa, Turkey \\ ${ }^{2}$ Department of Anesthesiology and Intensive Care, Lütfiye Nuri Burat State Hospital, Istanbul, Turkey
}

\begin{abstract}
Objectives: In this study, we aimed to evaluate the effects of isoflurane and sevoflurane on cerebral ischemia in patients undergoing intracranial tumour surgery by measuring protein S-100B in serum. Patients undergoing intracranial surgery are at risk for cerebral ischemia. The presence of S100-B in serum is an early and the most sensitive determinant of cerebral ischemia.

Methods: Twenty patients, scheduled for elective, intracranial tumor surgery were enrolled in this prospective and randomized study. Anaesthesia induction was performed with thiopental, fentanyl and vecuronium. In the maintenance, isoflurane or sevoflurane was administered in a minimum alveolar concentration of $0.8-1.2 \%$. Peripheral blood samples were taken at 9 different times to measure protein S-100B levels.

Results: Demographic data, heart rate, systolic arterial pressure, mean arterial pressure and the deviations in the end-tidal carbon dioxide were similar in the study groups $(p>0.05)$, whereas diastolic arterial pressure was found to be significantly decreased in isoflurane group after the intubation, and there was an increase in the sevoflurane group $(p<0.05)$. Also there was no significant difference between the groups regarding protein S-100B levels.
\end{abstract}

Conclusions: It was concluded that isoflurane and sevoflurane have similar neuroprotective effects against cerebral ischemia and sevoflurane may be a good alternative to isoflurane.

Keywords: protein S-100B, intracranial tumor, inhalational anaesthetics

$\mathrm{P}$ atients undergoing intracranial surgery are at risk for cerebral ischemia. Therefore, the aim of neuro-anaesthetics is to provide adequate cerebral perfusion during surgery [1]. In patients with increased intracranial pressure (ICP), due to cerebral tumors it is accepted that volatile anaesthetic agents are effective in the protection of cerebral ischemia that may develop due to decrease in systolic arterial pressure (SAP) [2].

Isoflurane's cerebral protection mechanisms in- clude reduction of cerebral metabolic rate (CMR) and metabolic suppression, inhibition of sympathetic activity, reduction of glutamate receptors which are prevent calcium flow, and suppression of excitotoxicity of calcium cascade [3]. It is thought that isoflurane may be secondary to direct vasodilatation or to reduction in CMR by the increase in cerebral blood flow (CBF) reduction [4]. Isoflurane has been reported to cause cerebral protection similar to barbiturates by depressing CMR, and it was shown that it reduce cere- 
bral energy metabolites more slowly than other anaesthetics during incomplete global ischemia and critical cerebral blood flow. In addition, isoflurane, similar to other volatile anaesthetics, reduces CMR in the cerebral cortex and electroencephalography (EEG) findings supports it is neuroprotective effects [4].

Sevoflurane's capacity to increase CBFwhile maintaining the cerebral autoregulation makes it an attractive agent for the preservation of neuronal function. In addition, the positive effect of sevoflurane to stabilize CBF and cerebral metabolism may be an important reason for choosing it as a neuroprotective agent when compared to other anaesthetics [5]. In protection against cerebral ischemia, sevoflurane is determined to decrease the damage that occurs with focal cerebral ischemia and the CMR, the reduction in local $\mathrm{CBF}$ has been found to be lower than isoflurane $[6,7]$. Isoflurane and sevoflurane are shown to significantly reduce the cerebral infarct area and improve neurological function after cerebral ischemia [8].

Cerebral ischemic damage is a complex mechanism. Energy metabolism disorder, oxygen free radical damage, inflammatory reactions and apoptosis are the some of mechanism [9]. During cerebral ischemia, the cerebral blood barier (BBB) is damaged due to endothelial cell death. Cytosolic content released from damaged brain tissue has the potential to pass through the damaged BBB. This shows that proteins release from the brain into the plasma can be used to determine the onset and size of cerebral ischemia [10].

Ideal biochemical serum markers should be very specific and sensitive in central nervous system (CNS) injuries, and after the damage, they should only be released from the CNS tissues and mixed into the blood stream by passing through the BBB [11]. Different biochemical substances were investigated to find an spesific indicator of cerebral cell damage. S-100B is a protein that binds to calcium, mainly found in the brain grey matter, especially in astrocytes and Schwann cells [12].

There is very little information about how the S$100 \mathrm{~B}$ passes through the $\mathrm{BBB}$ and is mixed into the blood. The molecular weight of the S-100B $(21,000$ Dalton) is high, which limits it to pass through the $\mathrm{BBB}$. Therefore, the increase in S-100B is probably due to the combination of astroglial cell membrane integrity, BBB dysfunction and early brain edema [13, 14]. S100B has been shown in serum after brain injury
$[15,16]$. The presence of S100-B in serum is an early and the most sensitive determinant of cerebral ischemia, which is known today [16-18]. Some studies have evaluated serum S100B during surgical manipulation; after aneurysm surgery [19] and elective meningioma resection [20]; increased serum S100B levels were reported to correlate with poor neurological outcome and post-craniotomy brain damage.

The aim of this study was to compare the effects of isoflurane and sevoflurane on cerebral ischemia in patients undergoing intracranial tumor surgery by measuring protein S-100B levels.

\section{METHODS}

After obtaining approval from local ethics committee, 20 patients from ASA (American Society of Anaesthesiologists) I-III class, who were to be operated under elective conditions due to intracranial tumor were enrolled in our study. Exclusion criteria were refused to participate, previous intracranial mass surgery, emergency surgery, patients who developed air embolism during the operation or who had a history of chemotherapy, stroke, cardiopulmonary resuscitation and head trauma. Patients with chronic renal failure (creatinine $>200 \mathrm{mmol} / \mathrm{I}$ ) were also excluded due to potential interference. Patients were randomly allocated to receive either isoflurane (Group $\mathrm{I}, \mathrm{n}=10$ ) or sevoflurane (Group $\mathrm{S}, \mathrm{n}=10$ ) using sealed enveloped. Peripheral arterial catheter was inserted after electrocardiography (ECG), peripheral oxygen saturation $\left(\mathrm{SpO}_{2}\right)$ and non-invasive blood pressure monitoring in the operation room. Following general anaesthesia induction and intubation, a central venous pressure catheter inserted.

Study data and medical records were collected prospectively. The demographic data of patients, heart rates (HR), SAP, diastolic arterial pressure (DAP), mean arterial pressure (MAP) and $\mathrm{SpO}_{2}$ baseline values were recorded before induction of general anaesthesia. During surgery, HR, SAP, DAP, MAP, $\mathrm{SpO}_{2}$, central venous pressure (CVP), end-tidal carbon dioxide (EtCO2) were monitored continuously. The measurements were made in 12 periods. They were recorded before induction of anaesthesia (BI), after intubation (AI), during skull clamping (SC), during skin incision (SI) during craniotomy (CT), during dura 
incision (DI), during tumor resection (TR), during dura suture (DS), during the bone placement (BP), during skin suture (SS), before extubation (BE), and after extubation (AE).

In order to suppress sympathetic response, 2 mg. $\mathrm{kg}^{-1}$ lidocaine and for sedation $0.03 \mathrm{mg} \cdot \mathrm{kg}^{-1}$ midazolam was given intravenously (i.v.). Anaesthesia induction was performed with sodium thiopental (3-5 mg.kg-1 $)$, fentanyl $\left(2 \mu \mathrm{g} \mathrm{kg}^{-1}\right)$ and vecuronium bromide (0.1 mg. $\left.\mathrm{kg}^{-1}\right)$. In the maintenance, the volatile anaesthetic (0.8-1.2 MAC) was given in a mixture of $50 \%$ oxygen-air according to the study group. The need for additional doses of muscle relaxant agent was determined according the response to the train-of-four. Vecuronium bromide (0.02 mg. $\left.\mathrm{kg}^{-1}\right)$ and fentanyl (1 $\left.\mu \mathrm{g} . \mathrm{kg}^{-1}\right)$ were administered i.v. as required .At the end of the operation, patients were extubated and transferred to Neurosurgical Intensive Care Unit.

\section{S-100 B Measurement}

Venous blood samples were taken at 24 hours before surgery (BS), before anaesthesia induction (BI), during tumour resection (TR), recovery room (RR) and at postoperative $3^{\text {rd }}(\mathrm{P} 3), 6^{\text {th }}(\mathrm{P} 6), 12^{\text {th }}(\mathrm{P} 12), 24^{\text {th }}$ (P24) and $48^{\text {th }}$ (P48) hours. The blood samples were centrifuged for 10 minutes, the serum was separated and the samples were coded and stored at $-50^{\circ} \mathrm{C}$ for further processing. After all the samples were collected, serum was brought to room temperature to measure S-100B. For measurement, the Nexus DX ${ }^{\mathrm{TM}}$ S-100 test kit was used. Enzyme immunoassay (ELISA) technique was used to measure S-100B in serum with this kit. The Nexus DX ${ }^{\mathrm{TM}} \mathrm{S}-100$ test kit is highly specific for $\beta$ subunit of the protein S-100 and is sensitive over $95 \%$.

\section{Statistical Analysis}

Statistical analysis of the study data was performed with the Statistical program pack for the Social Sciences 21 (SPSS, Harmony, New York, Il, USA) by the Department of Biostatistics, all data were expressed as average $\pm \mathrm{SD}$. The Mann-Whitney U test was used for statistical analysis. Statistical analysis was performed using Wilcoxon series comparisons. In all statistical analyses, two-way hypothesis tests and a level of significance for $p<0.05$ were accepted.

\section{RESULTS}

There was no statistically difference in terms of demographic data and duration of surgery between the two groups $(p>0.05)$, (Table 1). When we compared groups, there was no significant difference in terms of HR. When we compared the two groups, the changes in SAP and MAP were similar, while it was observed that the DAP only decreased Group I, and an increased Group S after intubation $(p<0.05)$ (Fig. 1). There was no significant difference between the groups regarding CVP and $\mathrm{SpO}_{2}$ values.

In Group I, there was a significant increase in $\mathrm{S}$ 100B levels in all periods except the BI period $(p<$ 0.01). In Group S, S-100B levels significantly increased in the periods of IA, RR, P3, P6, P12, P24 $(p<0.05, p<0.01, p<0.05, p<0.05, p<0.01, p<$ 0.05 ; respectively) (Fig. 2).

\section{DISCUSSION}

In intracranial tumor surgery, the anaesthetic

Table 1. Demographic data of the patients and duration of surgery

\begin{tabular}{lcc}
\hline & $\begin{array}{c}\text { Isoflurane Group } \\
(\mathbf{n}=\mathbf{1 0})\end{array}$ & $\begin{array}{c}\text { Sevoflurane Group } \\
(\mathbf{n}=\mathbf{1 0})\end{array}$ \\
\hline Gender (M/F) & $3 / 7$ & $4 / 6$ \\
Age (year) & $54.6 \pm 18.4$ & $44.4 \pm 15.0$ \\
Weight (kg) & $67.4 \pm 11.9$ & $69.7 \pm 12.4$ \\
Length (cm) & $164.7 \pm 11.0$ & $169.2 \pm 8.3$ \\
Duration of the surgery (min) & $373.0 \pm 102.8$ & $300.0 \pm 104.8$ \\
\hline
\end{tabular}

Data are shown as mean \pm standard deviation or number. $\mathrm{M}=$ Male, $\mathrm{F}=$ Female 


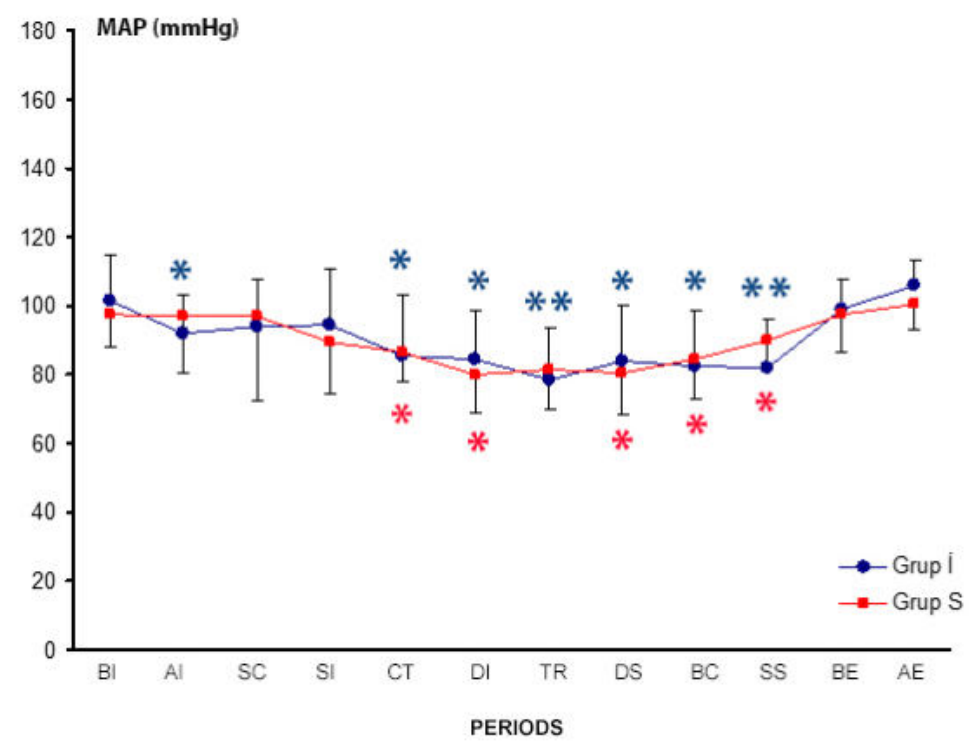

Fig. 1. Mean arterial pressure (MAP) values. Group I = Isoflurane group, Group S = Sevoflurane group, BI = before anaesthesia induction, $\mathrm{AI}=$ after intubation, $\mathrm{SC}=$ during skull clamping, $\mathrm{SI}=$ during skin incision, $\mathrm{CT}=$ during craniotomy, $\mathrm{DI}=$ during dura incision, $\mathrm{TR}=$ during tumor resection, $\mathrm{DS}=$ during dura suture, $\mathrm{IB}=$ during bone closure, $\mathrm{SS}=$ during skin suture, $\mathrm{BE}=$ before extubation, $\mathrm{AE}=$ after extubation. ${ }^{*} p<0.05, * * p<0.01$

Group I = Isoflurane group, Group S = Sevoflurane group,

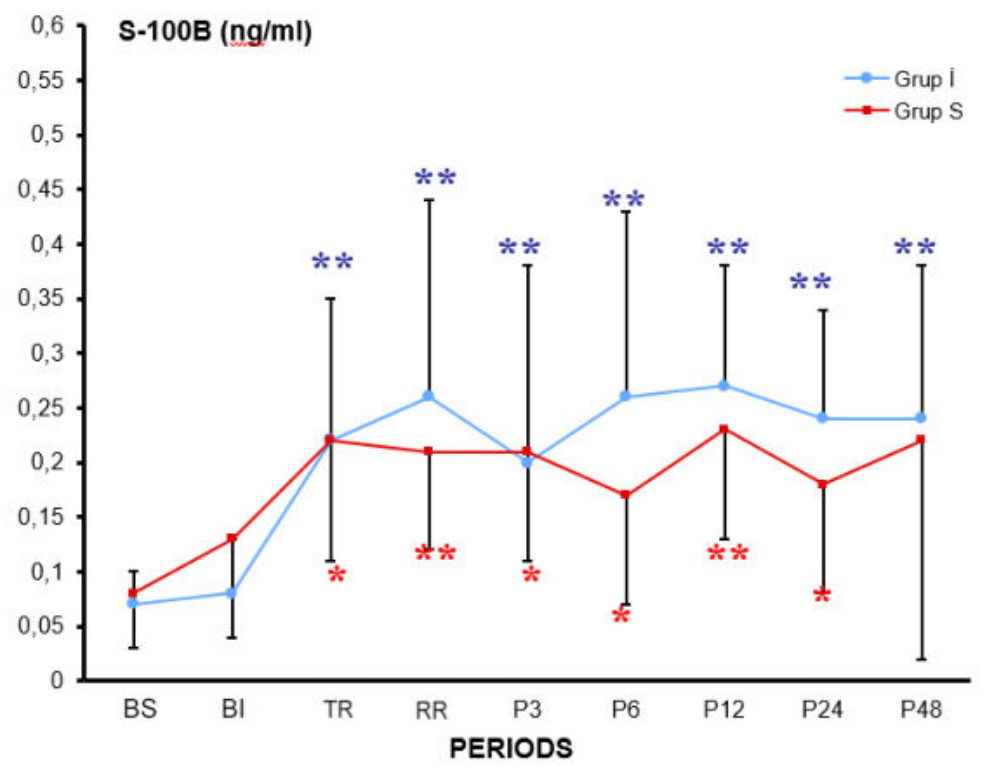

Fig. 2. Serum S-100B levels. Group I = Isoflurane group, Group $\mathrm{S}=$ Sevoflurane group, BS = 24 hours before surgery, BI = before anaesthesia induction, $\mathrm{TR}=$ during tumour resection, $\mathrm{RR}=$ in the recovery room, $\mathrm{P} 3=$ postoperative $3^{\text {th }}$ hour, $\mathrm{P} 6=$ postoperative $6^{\text {th }}$ hour, P12 $=$ postoperative $12^{\text {th }}$ hour, P24 $=$ postoperative $24^{\text {th }}$ hour, P48 $=$ postoperative $48 t^{\text {th }}$ hour. $* p<0.05$, $* * p<0.01$

approach involves certain objectives. These objectives are protecting the brain from ischemia, providing adequate hemodynamics to maintain the CPP maintaining the balance between oxygen delivery and the consumption of the brain. The cerebral autoregulation mechanism, is to keep CBF stable while SBP is between 50 and $150 \mathrm{mmHg}$, protects the brain against sudden changes in arterial pressure. Therefore, the effect of anaesthetic agents on cerebral autoregulation becomes important. 
Regarding the hemodynamic parameters, Negargar et al. [21], in their study DAP, SAP and MAP in the sevoflurane group were significantly lower than the isoflurane group. This might have been due to the effect of sevoflurane on cardiorespiratory reflexes. Our study showed that there was significant difference only DAP after intubation between the two groups. We could not make sense of this differece. This difference was clinically unimportant because HR, SAP and MAP were on normal ranges.

Sevoflurane, isoflurane, as compared with that provide more rapid induction and recovery advantages provided similar hemodynamic stability and less airway is considered to be a significant clinical potential for doing irritation [22]. The direct vasodilator effect of sevoflurane is considered to be $20 \%$ of isoflurane. This weak and vasodilator effect of sevoflurane may help explain why cerebral vasculature remains stable in response to changes in CPP during anaesthesia of sevoflurane, but this is disturbed due to extensive cerebral vasodilatation in isoflurane anaesthesia at the same concentration [21]. In addition, because of this weak vasodilation effect, sevoflurane is likely to cause a marked increase in ICP. This is a preferred feature for agents used in neurosurgical anaesthesia [22]. According to Artru et al.'s study [23] there is no increase in ICP during 0.51.0 and 1.5 MAC sevoflurane anaesthesia. Therefore, the protection is less in isoflurane because of vasodilatation. Summors et al. [24], in their study, found that cerebellar autoregulation was better in 1.5 MAC sevoflurane than 1.5 MAC isoflurane anaesthesia, and as a result, sevoflurane could bebe a better neuro-anaesthetic agent.

The chain of events that occur during cerebral ischemia results in neuronal death. The most common of these is the release of exitotoxic neurotransmitters. Reduction of the release of transmitters constitutes the mechanism of the drugs acting as neuron preservatives. The effect of sevoflurane on the release of neurotransmitters such as dopamine, glutamate and aspartate has been investigated by Toner et al. [25] They reported that when sevoflurane was administered at an average concentration of 1.7 MAC, it reduced release of neurotoxic transmitter and thus had a neuroprotective effect [25].

Martens et al. [26] have studied the role of serum S-100B and (Neuron-specific enolase) NSE in the recovery of consciousness after global cerebral ischemia. They reported that serum S-100B, as an independent biochemical marker, could provide information about acute global cerebral ischemia after brain injury, and that the results of serum S-100B were valid and reliable [26].

The release of cytochrome enzymes from the brain as a result of global cerebral ischemia shows widespread neuronal damage. After the acute injury, the S-100B is found in the serum for 24 hours and for 48 hours in the cerebro spinal fluid (CSF) [26]. There are also correlations between the volumetric measurements of the parenchymal destruction of the central nervous system (CNS) and first sample of the S-100B after brain injury. Therefore, S-100B concentrations should be interpreted within the scope of in damage-time relationship [27].

Two pathways have been proposed in the S-100B's transition from glial cells in the CNS to peripheral blood. The first is the absorption of CSF from CNS the veins. The second way is directly from the extracellular area to the local capillary. In their study, De Vries et al. [28] suggested that the second pathway was the main entrance due to the absence of the relationship between the cysternal and serum S-100B. Thus, they suggested that the increased concentration of serum S-100B showed dysfunction of the bloodbrain barrier [28].

In our study, the first significant increase in S100B levels found during tumor resection due to neuron damage. Although S-100B levels were higher in isoflurane group compared to sevoflurane group, but there was no statistically significant difference between the two groups. At the postoperative 48th hour, significant increases were observed in the isoflurane group, whereas the high levels in the sevoflurane group were not statistically significant. it was concluded that sevoflurane may have a protective effect on cerebral ischemia due to low levels of S100B compared to isoflurane group.

In our study, we found that the protein S-100B levels did not decrease as expected in the postoperative period, we considered that it might be due to the developing brain edema due to retraction, as Vries et al. [28] pointed out. In addition, if intracranial mass is large or if there is bleeding that will cause hypotension during the operation, may be responsible for the increase in S-100B. 


\section{Limitations}

The limitation of our study wasthe small number of patients. In our study we used special laboratory kit. Because of our limited financial resource we could not increase the number of patients.

\section{CONCLUSION}

As a result, we consider that in addition to isoflurane, which is one of the preferred volatile anaesthetic agents for intracranial tumor surgery, sevoflurane has similar effects on cerebral ischemia and can be used as a good alternative to isoflurane.

\section{Conflict of interest}

The authors disclosed no conflict of interest during the preparation or publication of this manuscript.

\section{Financing}

The authors disclosed that they did not receive any grant during conduction or writing of this study.

\section{REFERENCES}

[1] Morgan GE, Mikhail MS, Murray MJ. Neurophysiology and anesthesia.In: Morgan GE, Mikhail MS, Murray MJ (eds.) Clinical Anesthesiology. 4th edition., New York: Lange Medical Book/McGraw-Hill, 2006: pp.614-30.

[2] Matchett GA, Allard MW, Martin RD, Zhang JH. Neuroprotective effect of volatile anesthetic agents: molecular mechanims. Neurol Res 2009;31:128-134.

[3] Milde LN. Cerebral protection. In: Cucchiara RF, Black S, Mchenfelder JD (eds.). Clinical Neuroanesthesia. New York: Churchill Livingstone, 1998: pp.177-228.

[4] Heath KJ, Gupta S, Matta BF. The effects of sevoflurane on cerebral hemodynamics during propofol anesthesia. Anesth Analg 1997;85:1284-7.

[5] Hu XW, Zhang Y, Li WY, Liu J, Lia Y. Preconditioning with sevoflurane ameliorates spatil learning and memory deficit after focal cerebral ischemia-reperfusion in rats. Int J Dev Neurosci 2013;31:328-33.

[6] Lenz C, RebelA, Van Ackern K, Kuschinsky W, Waschke KF. Local cerebral blood flow local cerebral glucose utilization and flow metabolism coupling during sevoflurane versus isoflurane anesthesia in rats. Anesthesiology 1998;89:1480-8.

[7] Werner C, Möllenberg O, Kochs E, Schulte J am Esch. Sevoflurane improves neurological outcome after incomplete cerebral ischemia in rats. Br J Anaesth 1995;75:756-60.

[8] Mc Bride DW, Klebe D, Tank J, Zhang JH. Correcting for brain swelling effect on infarct volüme calculation after middle cerebral artery occlusion in rats. Transl Stroke Res 2015;6:32338.

[9] Wang H, Li P, Xu N, Zhu L, Cai M, Gao Y. Paradigms and mechanism of inhalational anesthetics mediated neuroprotection against cerebral ischemic stroke. Med Gas Res 2016;6:194-205. [10] Reynolds MA, Kirchick HJ, Dahlen JR, Anderberg JM, McPherson PH, Nakamura KK, et al. Early biomarkers of stroke. Clin Chem 2003;49:1733-9.

[11] Abdelmalak B, Cata J. Biomarkers: understanding, progress, and implications in the perioperative period. Adv Anesth 2010;28:161-86.

[12] Steiner J, Bogerts B, Schroeter ML, Bernstein HG. S100B protein in neurodegenerativ disorders. Clin Chem Lab Med 2011;49:409-24.

[13] Isobe T, Ishioka N, Okuyama T. Structural relation of two S-100 proteins in bovine brain; subunit composition of S-100a protein. Eur J Biochem 1981;115:469-74.

[14] Hachimi-Idrisi S, Van der Auwera M, Schiettecatte J, Ebinger G, Michotte Y, Huggens L. S-100 protein as early predictor of regaining consciousness after out of hospital cardiac arrest. Resuscitation 2002;53:251-7.

[15] Rosen H, Rosengren L, Herlitz J, Blomstrand C. Increased serum levels of the S-100 protein are associated with hypoxic brain damage after cardiac arrest. Stroke 1998;29:473-7.

[16] De Vries J, Snels SE, Menovsky T, Lemmens WA, De Reus $\mathrm{H}$, Lamers KJ, et al. Peri-operative levels of S-100 protein in serum: marker for surgical manipulation and postoperative complications. Minim Invasive Neurosurg 2003;46:33-6.

[17] Ingebrigten $\mathrm{T}$, Waterloo $\mathrm{K}$, Jacobsen EA, Langbakk B, Romner B. Travmatic brain damage in minor head injury: relation of serum S-100 protein measurements to magnetic resonance imaging and neurobehavioral outcome. Neurosurgery 1999;45:468-75.

[18] Herrmann M1, Vos P, Wunderlich MT, de Bruijn CH, Lamers KJ. Release of glial tissue-specific proteins after acute stroke : a comparative analysis of serum concentrations of protein S-100B and glial fibrillary acidic protein. Stroke 2000;31:26707.

[19] Schick U, Döhnert J, Meyer J-J, Vitzthum H-E. Prognostic significance of SSEP, BAEP and serum S-100B monitoring after aneurysm surgery. Acta Neurol Scand 2003;108:161-9.

[20] Einav S, Shoshan Y, Ovadia H, Matot I, Hersch M, Itshayek E. Early postoperative serum S100B levels predict ongoing brain damage after meningioma surgery: a prospective observational study. Crit Care 2006; 10:R141.

[21] Negargar S, Peirovifar A, Mahmoodpoor A, Parish M, Golzari SE, Molseqi H, et al. Hemodynamic parameters of lowflow isoflurane and low-flow sevoflurane anesthesia during controlled ventilation with laryngeal mask airway. Anesth Pain Med 2014;4:e20326.

[22] Shan J, Sun L, Wang D, Li X. Comparison of the neuroprotective effects and recovery profiles of isoflurane, sevoflurane and desflurane as neurosurgical pre-conditioning on ischemia/reperfusion cerebral injury. Int J Clin Exp Pathol 2015;8;2001-10.

[23] Artru AA, Lam AM, Johnson JO, Sperry RJ. Intracranial pressure, middle cerebral artery flow velocity and plasma 
inorganic fluoride concentrations in neurosurgical patients receiving sevoflurane on isoflurane. Anesth Analg 1997;85:58792.

[24] Summors AC, Gupta AK, Matta BF. Dynamic cerebral autoregulation during sevoflurane anesthesia: a comparison with isoflurane. Anesth Analg 1999;88:341-5.

[25] Toner CC, Connelly K, Whelpton R, Bains S, Michael-Titus AT, McLaughlin DP, et al. Effects of sevoflurane on dopamine, glutamate and aspartate release in an in vitro model of cerebral ischemia. Br J Anaesth 2001;86:550-4.

[26] Martens P, Raabe A, Johnsson P. Serum S-100 and Neuron- specific enolase for prediction of regaining consciousness after global cerebral ischemia. Stroke 1998;29:2363-6.

[27] Wunderlich MT, Ebert AD, Kratz T, Goertler M, Jost S, Herrmann M. Early neurobehavioral outcome after stroke is related to release of neurobiochemical markers of brain damage. Stroke 1999;30:1190-5.

[28] de Vries J, Thijssen WA, Snels SE, Menovsky M, Peer NG, Lamers KJ. Intraoperative volues of S-100 protein, myelin basic protein, lactate and albumin in the CSF and serum of neurosurgical patients. J Neurol Neurosurg Psychiatry 2001;71:671-4. 